\title{
Simulation of Control in Elderly Household Environment
}

\author{
Daniel Siman, Stanislav Krajňák, Ondrej Biroš, Dušan Šimšík * \\ 'Department of Automation, Control and Human Machine Interactions, Faculty of Mechanical Engineering, Technical University of Košice, \\ Letná 9, 04200 Košice, Slovak Republic
}

\section{KEY WORDS}

Simulation, elderly household, control, automation.

\begin{abstract}
Article deals with SCADA visualization software PROMOTIC as tool for simulation for controlling seniors household. This article presents sensor network proposal according to specific requirements. The basic protocols in sensor network are 1-wire and zigbee protocol. We describe basic blocks in PROMOTIC and its usage in our application. Control algorithms are written in script language VBScript.
\end{abstract}

\section{Introduction}

A growing number of older people, especially in Europe, move into the high level issue which increase the actions of research in the field of telemedicine, automation. New services and ICT technology became a part of the effort for the solutions of social system in European countries. One of the projects dealing with these issues was also MonAMI project [1]. The goal of MonAMI project was to demonstrate that accessible and useful services based on ICT, allowing the people with disabilities and elderly to increase autonomy, safety, and quality of their lives, can be delivered in mainstream systems and platforms. The MonAMI platform (the technology and services), which is a result of this project were installed and tested with perspective users in real conditions i.e. the elderly household environment.

Research team used user centered design for installation plans. The realization plan in every household was uniquely configured by technician to the needs of user and career. The realization of this plan - MonAMI platform installation was performed in five steps:

1) Each user was visited by interviewer and the technician who drew the sketch of the household to determine the system and sensors network location.

2) Pre-installation - the wiring and the devices that need an electrical and certificated installations, e.g. gas sensor or smoke sensor, were performed by electricians cooperating with technicians.

3) The internet connection was established.

4) Installation of sensors, actuators, social alarm device and residential gateway performed by technicians following the installation and sketch plan.

5) Launching the system, actuators and sensors, configuration of the system to the user's and carer's needs was performed.

Usually, the motion sensor was placed in the corridor and in the living room of the apartment. Temperature sensors were usually placed in the bedroom and living room. However, placement of the sensors depended on individual needs of each user, carer and especially from ground plan and architecture of the household. For successful 
and reliable deployment of MonAMI system in real conditions - elderly household environment - this was very difficult in terms of design, technological and implementation point of view.

Therefore, we decided to use virtualization and simulation program through which it is possible to design an optional distribution of sensor network and control system. In the following part of the article authors would like to show design and simulation of control on an example.

\section{Sensors Network and Control}

We describe design of sensors network for flat consisting of 3 big rooms, kitchen, hall, bathroom and toilet had been chosen. (Fig. 1)

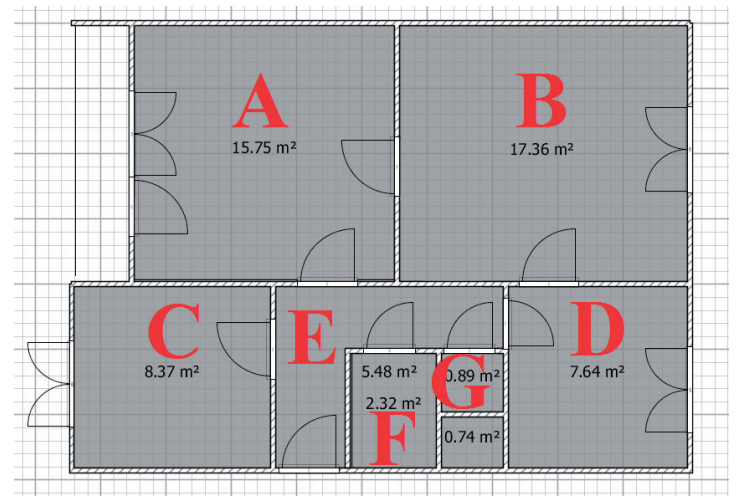

Fig. 1: A- living room, B - dining room, C-bedroom, D - kitchen, $E$ - hall, F-bathroom, $G$ - toilet.

\section{A. Sensors network desing}

The required functions for the designed sensors network are information about light conditions, temperature, user location, presence of smoke and special pressure pad located in the bed of the user. Another parameter is time. According to different hours during day system is reacting differently. Lightning conditions and temperature is sensing in every big room $(A, B, C, D)$. Smoke detector is located in kitchen (D), pad sensor is located in bedroom (C).

Localisation of user (senior) is working on trigonometry principle. Devices for localisation are based on Zigbee locators. Locators receive signals from device, which user is carrying on his wrist bracelet. In every room there are 2 locators. They receive information about power of signal and sending information to the central computer. Software in computer counts distance and user location from three or more signal power information.
This algorithm has not been implemented yet.

Temperature is regulated through actors placed on radiators. Basic setup for the temperature in rooms $A, B$ and $D$ is from 7.00 am to $10 \mathrm{pm}$ is $25^{\circ} \mathrm{C}$ and from $10 \mathrm{pm}$ to $7 \mathrm{am}$ is $20^{\circ} \mathrm{C}$. In bed room (room C) temperature can be set in range form $17^{\circ} \mathrm{C}$ to $28^{\circ} \mathrm{C}$. When temperature rise more then set temperature, radiators will be automatically turned off.

Lightning condition in all rooms are regulated with shutter form $7 \mathrm{am}$ to $5 \mathrm{pm}$. The shutter is controlled by the information from lightning sensors. The value from light sensor is in Lux units and should be 200 lx, which is predefined value. Between $4 \mathrm{pm}$ and 10pm lightning condition are ensured by light actuators. Besides light sensors, lights are controlled by movement sensors too when senior is in the room, light is going automatically on.

Between 10pm and 7am we assume that senior is sleeping and lights are working in muted mode. This is ensured with LED lights, which in case of normal mode shine on $100 \%$. In the night lights are working on $50 \%$ to increase comfort in case of night waking. LED lights are placed in hall, bedroom, bathroom and toilet $(C, E, F, G)$. LED lights in the night are controlled by pressure pad in seniors bed. After detecting that senior is getting up all LED lights start to shine on 50\% intensity.

Because of the safety reason, sensors network contains one smoke detector placed in kitchen (room D). Besides that, there are sound and light alarms placed in 5 rooms $A, B, C, D, E$ (Fig. 1).

\section{B. Technologies}

In network proposal 2 communication protocols are used - wireless technology ZigBee and wired protocol 1-Wire. Advantages of wireless protocol Zigbee are easy installation, digital data transmission, reliability of data transmission and short distance of transmission [2]. 1-Wire has been chosen because devices are powered through the same cable as is used for communication[3]. Based on these properties we designed the following network proposal. As a central unit is used standard notebook or desktop. On the computer ZigBee coordinator and 1-Wire HUB is connected. On the 1-Wire HUB are networked all sensors - temperature, pressure pad and shutter actors which are also powered through 1-Wire. Others sensor and actuators are connected to the computer through ZigBee coordinator and 4 ZigBee routers. 


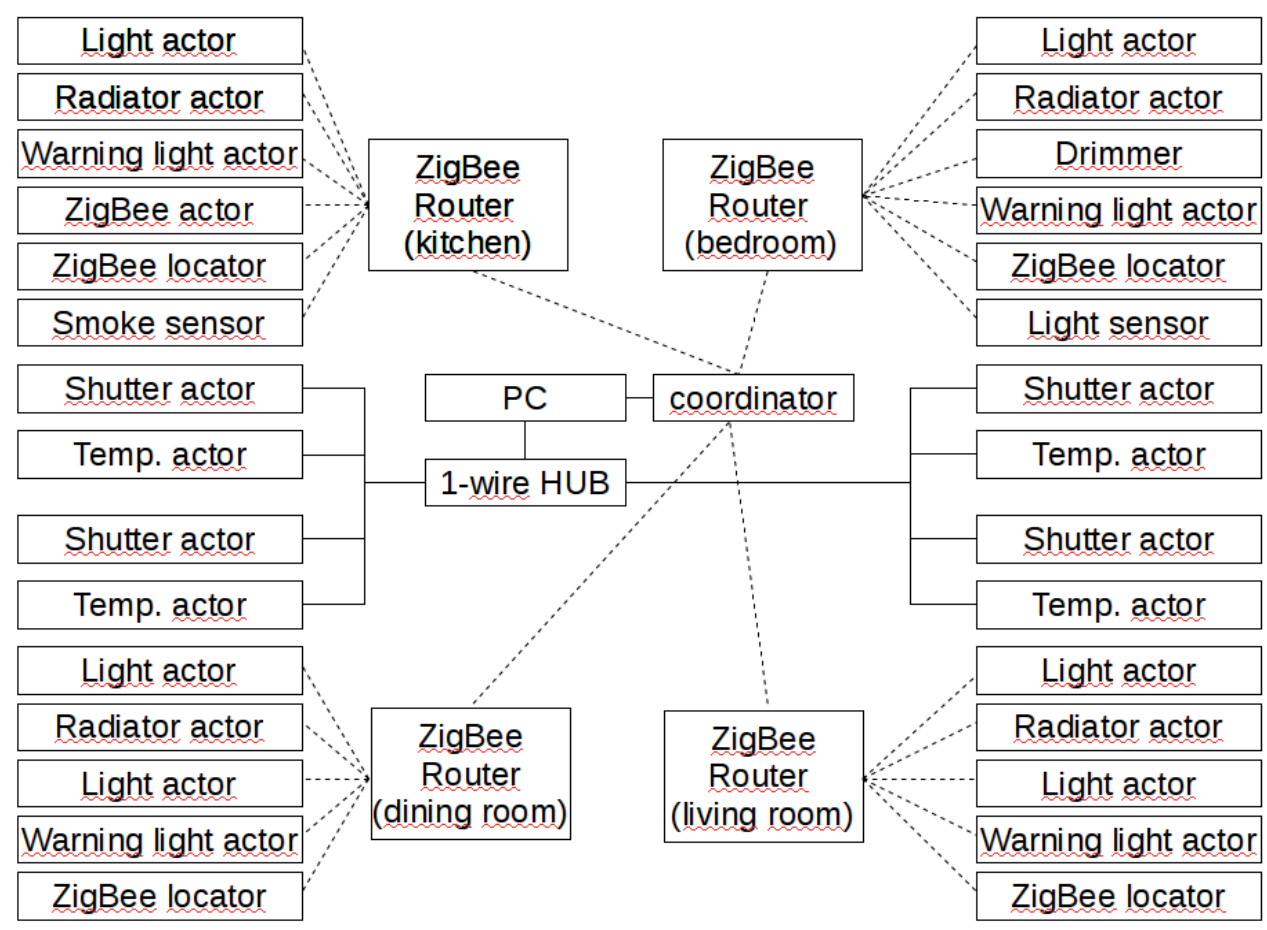

Fig. 2: Sensors network scheme

\section{Visualization}

Visualizations is created in software environment called PROMOTIC (MIRCOSYS). It is complex SCADA object software for control, monitoring, technological and industrial processes visualization. Software supports Windows operating systems, especially 8/7/Nista/XP/XPe/2003-8Serve r. PROMOTIC allows developers and researches effectively create distributed and open applications according to precise requirements [4].

Process of visualisation starts with creating new PROMOTIC application with name Domacnost_seniorov.pra. Advantage of PROMOTIC is that it creates whole folder for every project and there is no need to configure anything in file system, also basic setup is set by software itself [5].

\section{A. Promotics application objects}

PROMOTIC offers the possibility of creating objects. In our type of application we need to create flat. Flat consist of three objects. Byt (flat) is object type PmPanel, Timer type PmTimer and object named Data type PmData. Object Byt contains application window with visualisation of application data. Data object contains variables for storing values. Handling these variables is possible by others objects - Timer and Flat. Data object is interface between Timer and Flat. In our application, object Data contains 40 variables, mostly with type Single. Timer object is for writing own script. Routine OnStart is for starting application. This routine sets the variables to startup or deafult values. Routine onTick is running periodically according to set periodicity. Main script running in this routine simulates behavior of household. Periodicity is set to 1 second in our simulation.

\section{B.Promotics graphical objects}

All graphics for our project is stored in object Byt. For every main room $(A, B, C, D)$ we created information window. Every window displays information about all parameters - actual temperature, desired temperature, radiator status, lightning status and shutter status. If actual temperature drops under desired, radiators start working - this is visualised by button Stav radiatora. Signal button Stav svetla informs about light status. Behaviour of the system depends on time of the day, startup time is set according to system time on the computer, where simulation is running. For the purposes of simulation, we created properties window, where we can change current day time. In simulation properties window we can also change the location of senior by changing object PmiWCheck in all roooms. 
Others two check boxes are for creating events for smoke detectors and seniors night waking. In case of night waking, light in rooms $C, E, F, G$ starts shining on $50 \%$ intensity [7].

\section{Control Algorithm}

The simulation algorithm shows reactions on internal and external changes. Software allows to simulate monitoring and controlling technological processes and can communicate with external resources too. This allows not only simulations but possibility to connect real sensors and actuators $\lceil 81$.

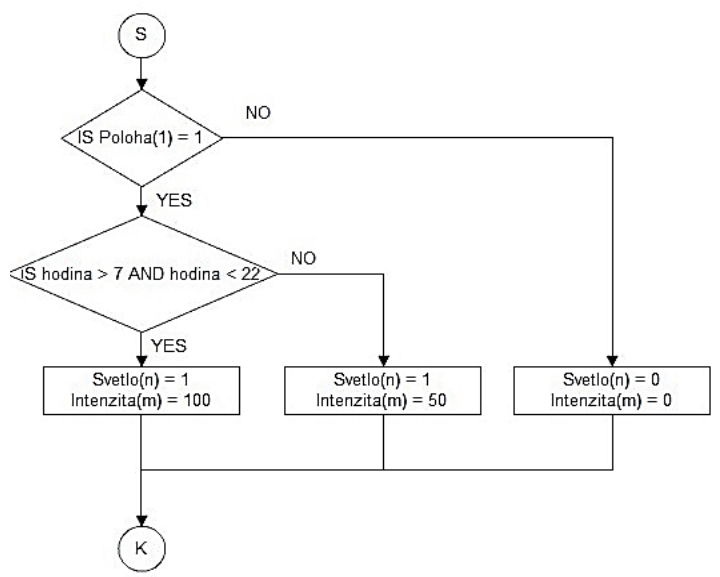

Fig. 3: Sensor network schema.
Dim nPoloha5, nTmp1, nSvetlo5, nlnt1

nPoloha5 = Round (oData.Item("checkbox6"), 1)

If $\mathrm{nPoloha5}=1$ Then

If nTmp1 $>7$ And nTmp1 $<22$ Then

nSvetlo5 = 1

nlnt1 $=100$

Else

nSvetlo5 = 1

nlnt1 $=50$

End If

Else

$$
\text { nSvetlo5 }=0
$$

$n \operatorname{lnt} 1=0$

End If

oData.Item("svetlo5") = Pm.Round(nSvetlo5,0.1)

oData.Item("Int1") = Pm.Round (nInt1,0.1)

\section{Conclusion}

Article discusses possibilities of simulations in software SCADA environment PROMOTIC on real example. We simulate wired and wirelles communication using zigbee and 1-wire. Network consists of sensors and actuators placed in seniors household. Control algorithm is created in script language VBScript. Visualization allows seeing changes in networks and environment. Sensors network consist of temperature sensor, lightning sensor, smoke detec

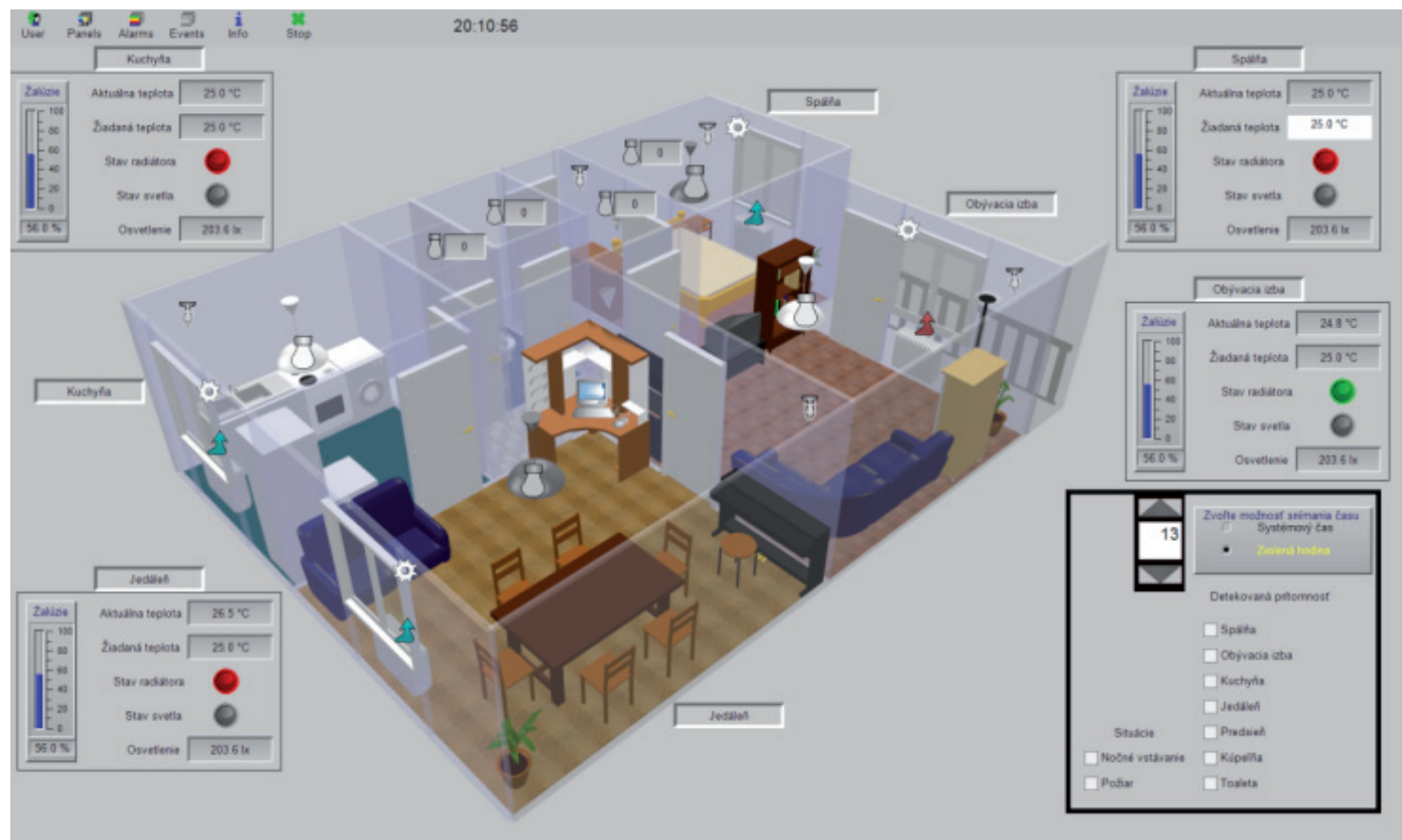

Fig. 4: Household Simulation Final View 
tor, pressure pad and senior location information. These information allows to control actuators - light actuators, radiator actuators, shutters, LED lights and alarms. Some of the sensors in simulation could be replace as variables, others had to be implemented as scripts. In home automation and monitoring are a lot of possibilities to expand the network. Promotic helps designers and developers to simulate variables, requirements, sensors in systems they want to implement. For testing, PROMOTIC can be also connected to external softwares and databes. It means part of simulation can be connected to real networks and sensors. Promotic supports several types of data exchange like OPC, DDE, ActiveX and communication through TCP/IP, HTTP, XML, DCOM.

\section{Acknowledge}

This paper is a part of work within Slovak grant agency VEGA „1/1162/11 - Teoretické princípy, metódy a prostriedky diagnostiky a rehabilitácie mobility seniorov", and it uses results from the 6th EC Framework Program - Priority 2.3.2.10 e-Inclusion "Mainstreaming on Ambient Intelligence "IST-5-0535147.

\section{References}

[1] MonAMl. Mainstreaming on Ambient Intelligence home page. Available online: $<$ http://www.monami.info/>

[2] KOYUNCE, H., YANG, A. H., A study of indoor positioning by using trigonometric and weight centriol localization techniques. [online]. október 2011, [cit. 2013-5-9]. Dostupné na internete: <http://www.academicjournals.org/ijcer/PDF/pdf2011/ October/Koyuncu\%20and\%20Yang.pdf>.

[3] WILAMOWSKI, B. M., IRWIN, J. D. Industial Communications Systems. 2. vyd. New York: CRC Press, 2011. 909 s. ISBN 978-1-4398-0281-6 [cit. 2012-5-9].

[4] AWTREY, D., SMITH, K., LISSIUK, D. Understanding 1-Wire Series. [online]. 19. augusta 2004, [cit. 2013-5-9] Dostupné na internete: <http://www.1wire.org/Files/ Articles/1-Wire-Design\%20Guide\%20v1.0.pdf>.

[5] MICROSYS, spol. s r.o. Co je PROMOTIC. [online]. [cit. 2013-5-9]. Dostupné na internete: <http://www.promotic.eu/cz/pmdoc/WhatlsPromotic/WhatlsPromotic. htm>.

[6] MICROSYS, spol. s r.o. Základní kostra aplikace. [online]. [cit. 2013-5-9]. Dostupné na internete: <http://www.promotic.eu/cz/pmdoc/EditorApp/Deschtm>

[7] MICROSYS, spol. s r.o. Editor aplikace. [online]. [cit. 2013-5-9]. Dostupné na internete: <http://www.promotic.eu/cz/pmdoc/EditorApp/Deschtm>.

[8] MICROSYS, spol. s r.o. Editor obrazů. [online]. [cit. 2013-5-9]. Dostupné na internete: $<$ http://www.promotic.eu/cz/pmdoc/EditorPan/Deschtm>

[9] VAINSTEIN, D. VBScript - The Basics. [online]. [cit. 2013-5-9]. Dostupné na internete:<http://www.onestopqa.com/resources/VB\%20Script\%20Basics.pdf>.

[10] modeling. In Proceedings of the 29th European Microwave Conference. Munich (Germany), 1999 , p. $174-177$. 